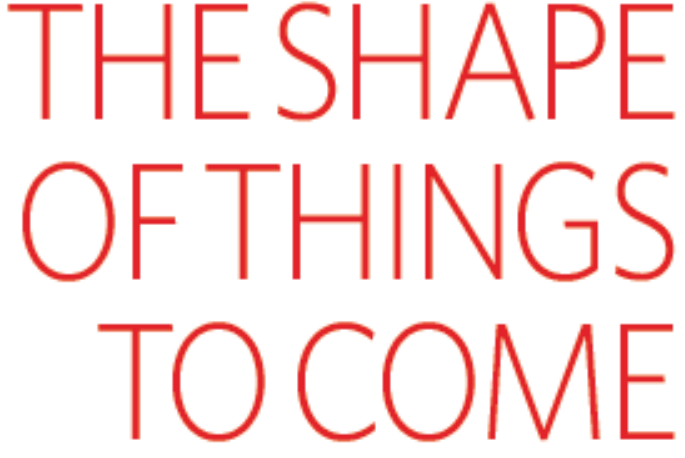

A number of fatal brain diseases are linked to misfolded proteins, an effect researchers are mimicking in the lab. But as they generate new versions of these malformed molecules, could they be creating a monster? Roxanne Khamsi finds out.

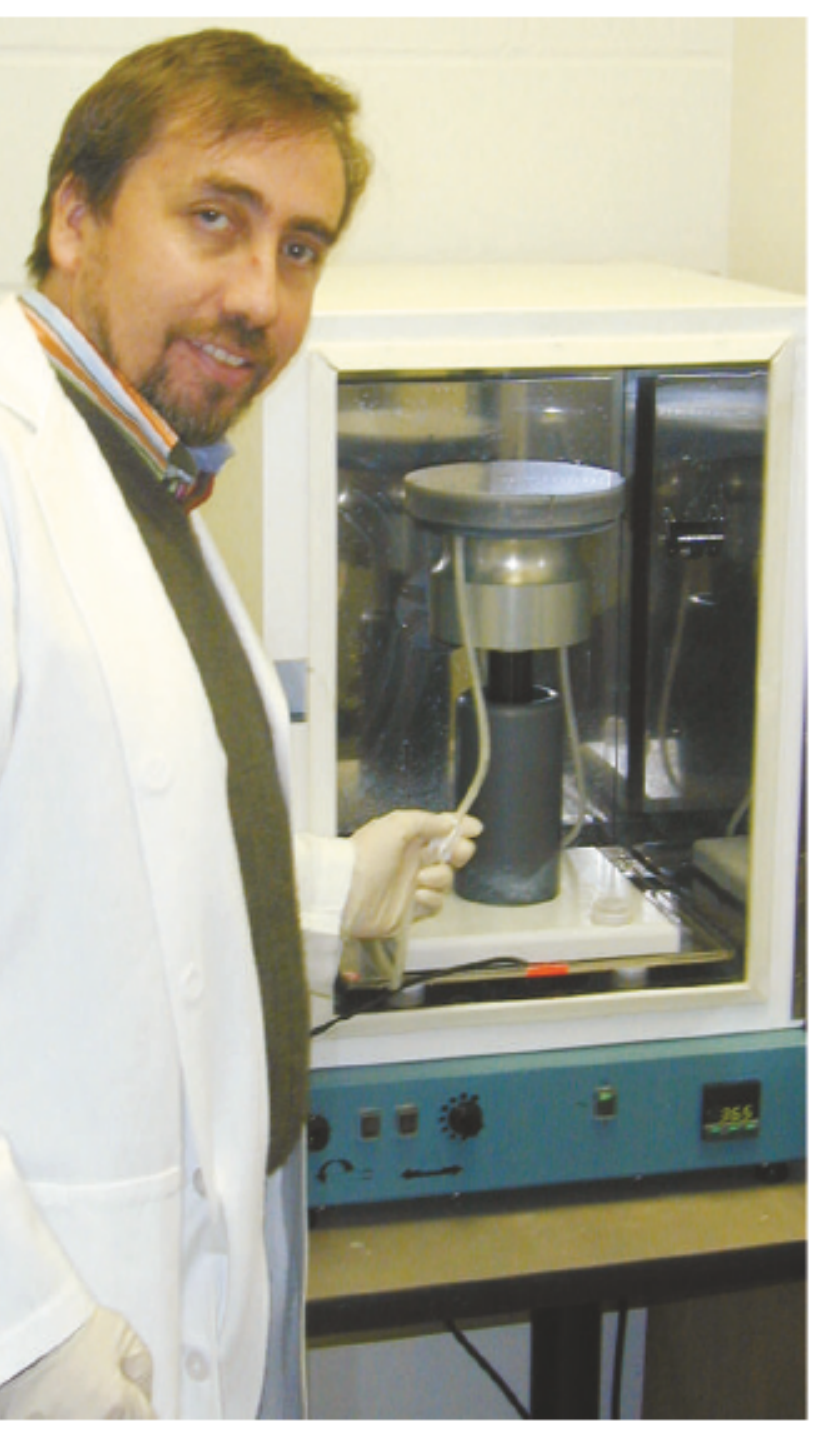

$\mathrm{n}$ a secure lab in Texas, five machines are purring away quietly. Working through the night, these boxes churn out billions of malformed proteins. A seemingly odd thing to massproduce, these distorted molecules are at the heart of research into a family of diseases that destroy the brain.

The equipment was devised by Claudio Soto ${ }^{1}$, a biologist at the University of Texas Medical Branch in Galveston, who works on prion protein, a naturally occurring molecule. Misfolded versions of this protein are thought to cause conditions such as mad cow disease and its human equivalent, Creutzfeldt-Jakob disease (CJD). Such abnormal prions are infectious and, when ingested, make their way to the brain, where they slowly distort the natural prion proteins, causing disease and, ultimately, death.

But this conversion process takes a long time - in humans it can be more than a decade before enough abnormal prion has been made to cause disease, making it hard for scientists to investigate the diseases. Soto's machines have changed that: they can quickly turn a mass of normal proteins into twisted imitations of their former selves.

${ }^{\alpha}$ We can mimic the process of prion replication that normally takes a year in the brain within a matter of hours in the test tube," says Soto. And that acceleration is allowing researchers to experiment with the abnormal prions, gaining fresh insight into how they cause disease. But it begs one important question: is it safe?

Collectively, the diseases linked to infectious prions are called transmissible spongiform encephalopathies, or TSEs, because of the spongy appearance they give the brain. Most TSEs are species-specific. Scrapie, for example, occurs in sheep; CJD in humans; and chronic wasting disease (CWD) in deer and elk. But some TSEs have hopped from one species to another - mad cow disease, for example, is believed to have jumped the 'species barrier' to cause disease in both cats and humans.

Given that the abnormal prions are notoriously hard to destroy - they resist temperatures as high as $120^{\circ} \mathrm{C}$ and are not broken down by the enzymes that usually degrade proteins - is it wise to be creating new types of them in the lab?

Like all prion research, Soto's work is carried out under strict biosafety conditions. He argues that the risk of any prions escaping is very low. "The potential

Rapid response: ClaudioSotodemonstrates his equipment for mass-producing abnormal prion proteins. benefits are much greater than the risk," he argues, adding that the work his team is doing could help predict whether a TSE is likely to jump between species.

Other researchers agree. They say that making prions in the test tube will help them tackle key problems such as why one type of abnormal prion behaves differently from another. "It's one of the most burning questions in the entire field," says Adriano Aguzzi, a prion researcher at the University Hospital of Zurich in Switzerland.

Scientists have long explored the question of whether TSEs can jump between species. Although a particular TSE spreads efficiently within a species, researchers have found it much harder to infect one species with the abnormal prion from another. This led to the idea of a species barrier that limited such infections in the wild.

\section{Broken barriers}

But that view was challenged in the late 1980 s, when Britain's cow herds were struck by a new TSE: mad cow disease, or bovine spongiform encephalopathy. Scientists suspect that the species jump was caused by the farm animals being given feed created from the rendered carcasses of scrapie-infected sheep. And the disease didn't stop there - it also seemed to jump from cows to humans, causing a condition called variant CJD.

Experts generally agree that abnormal prions from cows can convert normal ones in humans, and cite this as an example of a prion disease crossing the species barrier. So just how easily do infectious prions jump from one animal species to another? It's no idle question. Although governments have banned certain animal by-products from feed to restrict the transmission of prion disease among livestock, some experts say that there may be a need for further restrictions to prevent the possible spread of TSEs to species such as pigs, which are currently thought to be much less susceptible to prion disease under experimental conditions.

But in the 1990s, a new TSE emerged in UK cats, claiming the lives of more than 80 domestic animals. It even spread as far as zoo animals, reaching cheetahs, ocelots, pumas, lions and tigers. Again it was linked to the BSE prion, suggesting that the species barrier might be easier to breach than was once thought.

To get a clearer picture of infectious prions and their ability to jump species, researchers are turning to Soto's massproduction technique. In the brain, the abnormal prions tend to link together in chains, eventually forming visible tangles. But this limits the number of prions 

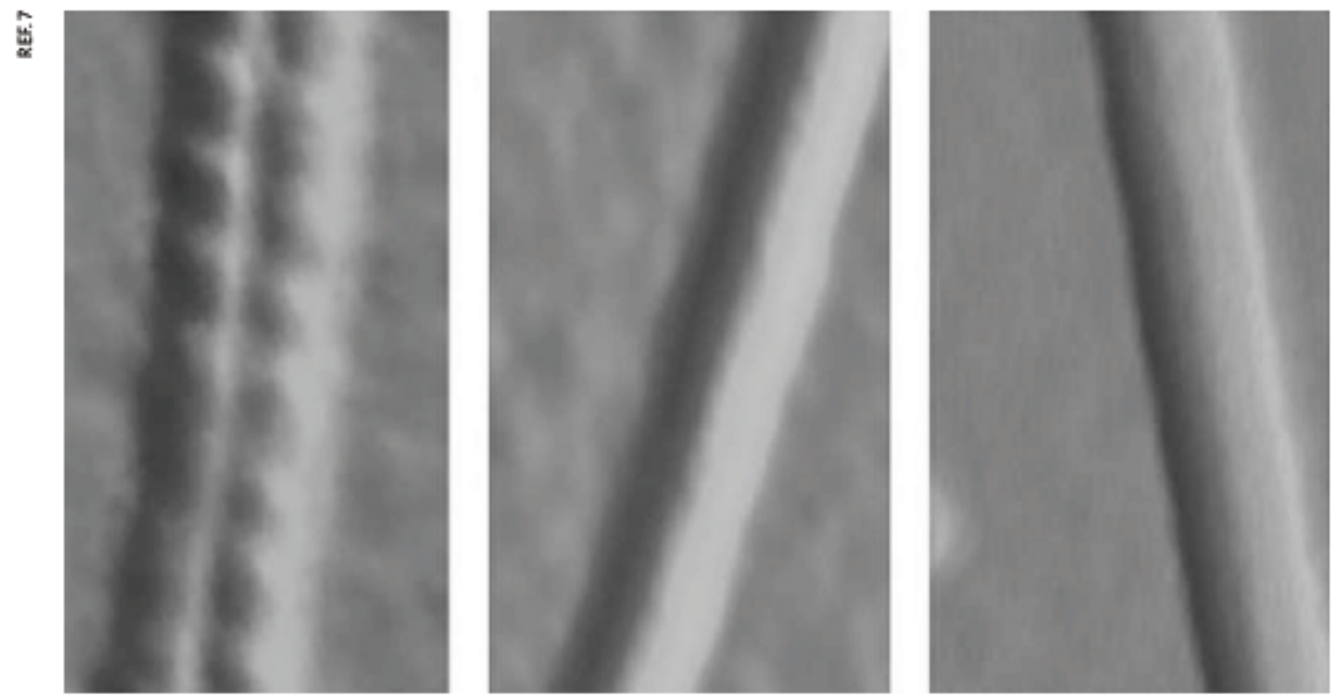

Twistedinto shape: just minor changes to a normal human prion protein (left) can change its threedimensional structure (right) to resemble the infectious, disease causing prion found in hamsters (centre).

free to convert normal proteins - only those at the end of the chains can cause the switch, making it a very slow process. In his protein-misfolding cyclic amplification (PMCA), Soto found a neat way to sidestep this problem.

The technique initially incubates a small amount of abnormal prion with an excess of normal protein, so that some conversion takes place. The growing chain of misfolded protein is then blasted with ultrasound, breaking it down into smaller chains and so rapidly increasing the amount of abnormal protein available to cause conversions. By repeating the cycle, the mass of normal protein is rapidly changed into misfolded prion.

\section{Tangled web}

Soto and his team have used the technique to probe the limits of the species barrier. In unpublished work, they incubated normal protein from lab animals such as mice with a range of infectious prions, including those that cause mad cow disease, scrapie and CWD. The resulting prions caused disease when injected into the brains of rodents. "The data from our experiments suggest that there is no absolute species barrier. You can always break it," says Soto. "It's just a question of how far you push the system."

Soto's lab is now extending these experiments to look at other possible species jumps, including that from infected deer to humans. Although eating meat from scrapie-infected sheep does not seem to cause prion disease in humans, the effects of eating venison contaminated with CWD remain unclear. It has not yet been proved that CWD can jump to humans, but studies have shown that injecting CWD prions into monkeys can cause disease ${ }^{2}$, says Paul Brown, former medical director of
"The

concept of an absolute

species

barrier is

probably a

myth." -

Paul Brown

the Laboratory of Central Nervous System Studies in Bethesda, Maryland. He stresses that CWD does not pose a public health risk as deer remains do not typically get cycled into the food chain.

"The concept of an absolute species barrier is probably a myth," says Brown, adding that there are simply "varying degrees of ease ${ }^{x}$ in terms of how readily the prions can be transmitted. Under experimental conditions, skunks, pigs and even gerbils seem susceptible to TSEs from other species ${ }^{3}$. As yet, researchers have not succeeded in infecting dogs or rabbits with a TSE.

\section{Taking the strain}

Another big question is what makes a particular prion 'strain' act in the way it does. Strains are defined by the characteristics of the illness they cause in a given animal, including incubation time and the type of damage done to the brain. Often, different strains will have distinctive biochemical properties although two strains within the same species can have the same amino-acid sequence and behave differently.

Byron Caughey and his team at the Rocky Mountain Laboratories in Hamilton, Montana, have been working on making prions in the test tube for more than a decade. In 1995, they showed that

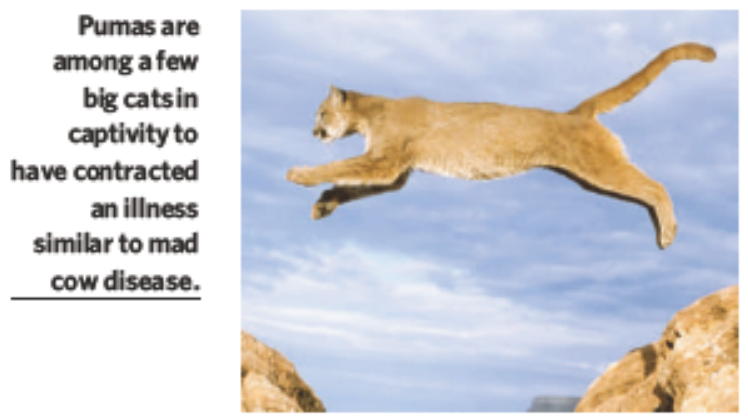

infectious prions made in the absence of cells retain strain-specific qualities, such as tending to convert only prions from the same species ${ }^{45}$, which suggests that no other cellular components are needed for the prion's activity.

Some studies suggest that the species barrier is dictated largely by the threedimensional structure of the abnormal prion species ${ }^{6}$. In other words, the given prion's structure has to be able to work with the native normal protein. By changing just two key amino acids in the proteins, Witold Surewicz of Case Western Reserve University in Cleveland, Ohio, and his team have created new prion fragments that defy the species barrier ${ }^{7,8}$. The result was new structures that could adopt the shape of prion fragments from a different species.

Using Soto's technique, such investigations into the species barrier will only accelerate. But as biologists mix normal and infectious prions from different species in the lab, they will create novel prions with unpredictable abilities. The risks of creating a 'super-strain' are not new - scientists recently debated the merits of recreating and tinkering with the virus strain that caused the $1918 \mathrm{flu}$ pandemic.

Proponents of the prion work say that the threat of creating an accidental monster is minimal. They stress that unlike the genetic manipulation of flu viruses, which could produce an inhaled superbug, similar work in prions is unlikely to produce infectious material that can be transmitted through the air.

Others point out that scientists have been creating new prion strains for many years - albeit in animals, rather than in the test tube. "I do not see the generation of new strains in cell-free systems as a fundamentally new type of biohazard," says Caughey.

And understanding how easily particular infectious prions can pass from one species to another will help officials design adequate safety measures to protect us and our food chain, says Soto. "It's very important to evaluate the danger and be prepared."

\section{Roxanne Khamsi reports for Nature} from New York.

1. Saborio, G. P, Permanne, B. \& Soto, C. Nature 411 810-813 (2001)

2 Marsh, R. F, Kincaid A. E, Bessen, R. A. \& Bartz, J.C. J. Wrol. 79, 13794-13796 (2005).

3 Brown, P. Transmissible Spongiform Encephalapathy as a Zonotic Disease (International Life Sclences Institute Europe, Brussels 2003).

4. Kocislo, D.A. et al Proc. Natl Aød Sci. USA 92, 3923-3927 (1995).

5 Bessen, R. A. etal Nature375,698-700 (1995).

6. Peretz, D etal. Neuron 34, 921-932(2002).

7. Jones. E.M. \& Surewicz, WK Cell 121,63-72 (2005).

8. Vanik, D.L, Surewicz, K A.\& Surewicz, W.K. Mol. Cell14, 139-145 (2004) 